\title{
Peptic Ulcer Disease in Elderly Population of Arar City, Northern Saudi Arabia
}

\author{
Mashael Jaza H Alshammari ${ }^{1}$, Omar Mohamed Bakr Ali ${ }^{2}$, Samar khaled al-shamlani ${ }^{1}$, Shada \\ Khaled Bashantoof ${ }^{3}$, Zahra Ali Qalib ${ }^{4}$, Bashayr Zayed Al-Amri ${ }^{5}$, Nora Henaf Hia Alrwely ${ }^{5}$, \\ Sulaiman Zayed S Alamri ${ }^{5}$, Abduljawad Salem S Alharbi ${ }^{6}$, Elham Hamid O Alfallaj ${ }^{7}$ \\ ${ }^{1}$ Faculty of Medicine, Northern Border University, KSA, ${ }^{2}$ Faculty of Medicine, Sohag University, \\ Egypt, ${ }^{3}$ Faculty of Medicine, Hail University, ${ }^{4}$ Faculty of Medicine, Uclan University, ${ }^{5}$ Faculty of \\ Medicine, Al Jouf University, ${ }^{6}$ Faculty of Medicine, King Abdulaziz University, ${ }^{7}$ Faculty of Medicine, \\ Almaarefa University
}

\begin{abstract}
:
Background: peptic ulcer disease (PUD) is a common disease of the digestive system. Peptic ulcer disease is a problem of the gastrointestinal tract characterized by mucosal damage secondary to pepsin and gastric acid secretion. It usually occurs in the stomach and proximal duodenum; less commonly, it occurs in the lower esophagus, the distal duodenum, or the jejunum. IT is a multifactorial health problem affecting almost all populations worldwide. The number of people who are $\geq 60$ years old increased worldwide. The elderly population is susceptible to various benign and malignant diseases. Peptic ulcer is among the common health problems that affect the elderly. Aim of the study: this study aimed to determine the prevalence and risk factors of PUD in elderly population of Arar city, Northern Saudi Arabia. Subjects and methods: this was a cross sectional study and conducted in five randomly selected primary healthcare centers in Arar city (KSA), from September 2017 to March 2018. It included 217 elderly patients. A questionnaire was designed for data collection about sociodemographic variables, smoking, BMI, chronic diseases and physician diagnosed peptic ulcer among participants. Results: our findings showed that out of 217 of the studied elders, $55.3 \%$ were females and $21.2 \%$ were suffered from peptic ulcer. There were significant relations between peptic ulcer with gender, marital status, educational level and smoking status, while there was an insignificant relation between peptic ulcer with age group and BMI group. On the other hand, there were significant relations between peptic ulcer and musculoskeletal disorders, kidney diseases and insomnia. While, there was insignificant relations between peptic ulcer and cardiovascular diseases, ischemic heart diseases, hypertension, neurological disorders, diabetes mellitus and psychological disorders. Conclusion: among the elderly participants $21.2 \%$ were suffered from peptic ulcer. There was a significant relation between peptic ulcer with gender, smoking status, musculoskeletal disorders, kidney diseases and insomnia. While, there was insignificant relations between peptic ulcer with age group and BMI group.
\end{abstract}

Keywords: peptic ulcer, smoking, obesity, pattern, elderly, Arar, Northern Saudi Arabia

\section{Introduction:}

Peptic ulcer disease (PUD) is defined as a break in the inner lining that usually occurs in the stomach and proximal duodenum. An ulcer in the stomach is known as a gastric ulcer while, that in the first part of the intestines is known as a duodenal ulcer ${ }^{[1]}$.Peptic ulcer disease is a common condition, although the majority of studies reported a decrease in the incidence or prevalence of PUD over time. The results of prevalence cross-sectional studies vary from a study to another ${ }^{[2]}$. A study from Sweden, reported cross-sectional data and represented the general population; the study thus included both symptomatic and asymptomatic PUD, the overall prevalence of PUD observed was $4.1 \% ; 19.5 \%$ of all PUD cases identified as asymptomatic ${ }^{[3]}$. PUD was a significant cause of morbidity and mortality in the elderly ${ }^{[4]}$. Increased incidence of side effects and medication interactions makes complications course much more serious in the elderly although their incidence was similar in younger patients ${ }^{[5]}$. H. pylori infection and the use of nonsteroidal anti-inflammatory drugs (NSAIDs) were the predominant causes of peptic ulcer. Kurata et al. ${ }^{[6]}$ in their study showed these two causes to account for 48 and 24 percent of cases, respectively. However, cytomegalovirus, tuberculosis, Crohn's disease, hepatic cirrhosis, chronic renal failure, sarcoidosis and myeloproliferative disorder were all associated with a greater risk of peptic 
ulcer disease ${ }^{[7]}$. Complications may include bleeding (in up to $15 \%$ of cases), perforation and blockage of the stomach ${ }^{[8]}$. Peptic ulcer disease remains a common condition, although reported incidence and prevalence are decreasing. The diagnosis of peptic ulcer disease is usually based on clinical features and specific tests (such as endoscopies or barium contrast $\mathrm{x}$-rays ${ }^{[9]}$. Typical symptoms of peptic ulcer disease include episodic gnawing or burning epigastric pain; pain occurrs two to five hours after meals or on an empty stomach and nocturnal pain relieved by food intake, antacids, or antisecretory agents [10].

This study aimed to determine the prevalence and risk factors of PUD in elderly population of Arar city, Northern Saudi Arabia.

\section{Subjects and Methods: \\ Study design and setting:}

The current study was a cross sectional study and it was conducted in Arar City in the Northern Province of Kingdom of Saudi Arabia, during the period from September 2017 to March 2018.

\section{Study participants:}

The population of the present study was consisted of 217 elderly patients attended five randomly selected primary healthcare centers in Arar City in the Northern Province of Kingdom of Saudi Arabia. The selected primary healthcare centers were reviewed regularly during the study period and all the elderly attending the centers during the study period invited to participate in this study. They were included in the study after taking an informed consent. Each person was interviewed separately and their files were examined to collect the needed data and fill the questionnaires. The elderly was defined as 60 years old or more.

\section{Data collection method:}

A predesigned questionnaire was used for data collection and included inquiries about sociodemographic data of the studied patients, smoking, body mass index (BMI), chronic diseases and doctor diagnosed peptic ulcer among them. Collecting patient's data was conducted through interviewing the participants and reviewing their medical files.

\section{Ethical consideration:}

Written informed consent after explaining the purpose of the study was obtained from all patients who participated in this study. The questionnaires used in data collection were anonymous and confidentiality of data was assured.

\section{The statistical analysis:}

The statistical analysis carried out using SPSS software for windows was version 16. Sample characteristics summarized as numbers and percentages for qualitative variables. ChiSquare test was used for testing the associations. A 5\% level was chosen as a level of statistical significance in all statistical tests used in this study.

\section{Results:}

Table 1 showed gender, age group, BMI group, marital status, educational level, smoking status and peptic ulcer in the studied population. $21.2 \%$ of the studied population was suffered from peptic ulcer. Out of 217 of the studied elders, 55.3\% were females. Most of the studied population were $60-70$ years old $(63.6 \%)$. The majority were obese (44.2\%), normal weight and overweight were $26.3 \%$ each, while low weight were only $3.2 \%$. $60.4 \%$ of the studied population were married, $35.9 \%$ widowed and only $2.3 \%$ divorced. Half of the studied population were illiterate $(50.2 \%), \quad 18.9 \%$ were primary educated, and university or higher educated were $13.4 \%$. Around two thirds were nonsmokers $(68.7 \%), 24 \%$ pervious smokers, and $7.4 \%$ were current smokers. Table 2 Illustrated the relation of gender, age group, BMI group, marital status, educational level and smoking status with peptic ulcer. The table showed significant relations between peptic ulcer with gender, marital status, educational level and smoking status, while it showed insignificant relations between peptic ulcer with age group and BMI group.Table 2 showed the relation of cardiovascular diseases, ischemic diseases, hypertension, musculoskeletal disorders, neurological disorders, diabetes mellitus, kidney diseases, psychological disorders and insomnia with peptic ulcer. It was clear from the table that there were significant relations between peptic ulcer and musculoskeletal disorders, kidney diseases and insomnia. On the other hand, the table showed insignificant relations between peptic ulcer and cardiovascular diseases, ischemic diseases, hypertension, neurological disorders, diabetes mellitus and psychological disorders. 
Table 1: socio-demographic characteristics, smoking status and peptic ulcer in the studied population. $\mathrm{N}=\mathbf{2 1 7}$

\begin{tabular}{|c|c|c|}
\hline & Frequency & Percent \\
\hline \multicolumn{3}{|l|}{ Gender } \\
\hline Female & 120 & 55.3 \\
\hline Male & 97 & 44.7 \\
\hline \multicolumn{3}{|l|}{ Age Group } \\
\hline $60-70$ & 138 & 63.6 \\
\hline $70-80$ & 59 & 27.2 \\
\hline$>80$ & 20 & 9.2 \\
\hline \multicolumn{3}{|l|}{ BMI Group } \\
\hline Low & 7 & 3.2 \\
\hline Normal & 57 & 26.3 \\
\hline Overweight & 57 & 26.3 \\
\hline Obese & 96 & 44.2 \\
\hline \multicolumn{3}{|l|}{ Marital status } \\
\hline Married & 131 & 60.4 \\
\hline Single & 3 & 1.4 \\
\hline Widow & 78 & 35.9 \\
\hline Divorced & 5 & 2.3 \\
\hline \multicolumn{3}{|l|}{ Education level } \\
\hline Illiterate & 109 & 50.2 \\
\hline Primary & 41 & 18.9 \\
\hline Intermediate & 17 & 7.8 \\
\hline Secondary & 21 & 9.7 \\
\hline University or higher & 29 & 13.4 \\
\hline \multicolumn{3}{|l|}{ Smoking Status } \\
\hline Smoker & 16 & 7.4 \\
\hline Non-smoker & 149 & 68.7 \\
\hline Ex-smoker & 52 & 24.0 \\
\hline \multicolumn{3}{|l|}{ Peptic ulcer } \\
\hline Yes & 46 & 21.2 \\
\hline No & 171 & 78.8 \\
\hline
\end{tabular}


Table 2: relation of socio-demographic characteristics and smoking status with peptic ulcer in the studied population. $(\mathrm{N}=217)$

\begin{tabular}{|c|c|c|c|c|c|}
\hline & & \multicolumn{2}{|l|}{ Peptic ulcer } & \multirow{2}{*}{$\begin{array}{l}\text { Total } \\
(\mathrm{N}=217)\end{array}$} & \multirow{2}{*}{$\mathrm{P}$ value } \\
\hline & & Yes $(\mathrm{N}=46)$ & $\begin{array}{l}\text { No } \\
(\mathrm{N}=171)\end{array}$ & & \\
\hline \multirow[t]{4}{*}{ Gender } & \multirow[t]{2}{*}{ male } & 12 & 85 & 97 & \multirow[t]{4}{*}{0.003} \\
\hline & & $26.1 \%$ & $49.7 \%$ & $44.7 \%$ & \\
\hline & \multirow[t]{2}{*}{ female } & 34 & 86 & 120 & \\
\hline & & $73.9 \%$ & $50.3 \%$ & $55.3 \%$ & \\
\hline \multirow[t]{6}{*}{ Age group } & \multirow[t]{2}{*}{$60-70$} & 28 & 110 & 138 & \multirow[t]{6}{*}{0.856} \\
\hline & & $60.9 \%$ & $64.3 \%$ & $63.6 \%$ & \\
\hline & \multirow[t]{2}{*}{$70-80$} & 14 & 45 & 59 & \\
\hline & & $30.4 \%$ & $26.3 \%$ & $27.2 \%$ & \\
\hline & \multirow[t]{2}{*}{$>80$} & 4 & 16 & 20 & \\
\hline & & $8.7 \%$ & $9.4 \%$ & $9.2 \%$ & \\
\hline \multirow[t]{8}{*}{ BMI group } & \multirow[t]{2}{*}{ low } & 0 & 7 & 7 & \multirow[t]{8}{*}{0.279} \\
\hline & & $0.0 \%$ & $4.1 \%$ & $3.2 \%$ & \\
\hline & \multirow[t]{2}{*}{ normal } & 12 & 45 & 57 & \\
\hline & & $26.1 \%$ & $26.3 \%$ & $26.3 \%$ & \\
\hline & \multirow[t]{2}{*}{ overweight } & 16 & 41 & 57 & \\
\hline & & $34.8 \%$ & $24.0 \%$ & $26.3 \%$ & \\
\hline & \multirow[t]{2}{*}{ obese } & 18 & 78 & 96 & \\
\hline & & $39.1 \%$ & $45.6 \%$ & $44.2 \%$ & \\
\hline \multirow[t]{8}{*}{ Marital status } & \multirow[t]{2}{*}{ married } & 20 & 111 & 131 & \multirow[t]{8}{*}{0.031} \\
\hline & & $43.5 \%$ & $64.9 \%$ & $60.4 \%$ & \\
\hline & \multirow[t]{2}{*}{ single } & 0 & 3 & 3 & \\
\hline & & $0.0 \%$ & $1.8 \%$ & $1.4 \%$ & \\
\hline & \multirow[t]{2}{*}{ widow } & 24 & 54 & 78 & \\
\hline & & $52.2 \%$ & $31.6 \%$ & $35.9 \%$ & \\
\hline & \multirow[t]{2}{*}{ divorced } & 2 & 3 & 5 & \\
\hline & & $4.3 \%$ & $1.8 \%$ & $2.3 \%$ & \\
\hline Educational status & illiterate & 22 & 87 & 109 & 0.034 \\
\hline & & $47.8 \%$ & $50.9 \%$ & $50.2 \%$ & \\
\hline & primary & 14 & 27 & 41 & \\
\hline & & $30.4 \%$ & $15.8 \%$ & $18.9 \%$ & \\
\hline & intermediate & 0 & 17 & 17 & \\
\hline & & $0.0 \%$ & $9.9 \%$ & $7.8 \%$ & \\
\hline & secondary & 6 & 15 & 21 & \\
\hline & & $13.0 \%$ & $8.8 \%$ & $9.7 \%$ & \\
\hline & university & 4 & 25 & 29 & \\
\hline & or higher & $8.7 \%$ & $14.6 \%$ & $13.4 \%$ & \\
\hline Smoking status & smoker & 10 & 6 & 16 & 0.0001 \\
\hline & & $21.7 \%$ & $3.5 \%$ & $7.4 \%$ & \\
\hline & non-smoker & 26 & 123 & 149 & \\
\hline & & $56.5 \%$ & $71.9 \%$ & $68.7 \%$ & \\
\hline & pervious & 10 & 42 & 52 & \\
\hline & smoker & $21.7 \%$ & $24.6 \%$ & $24.0 \%$ & \\
\hline
\end{tabular}


Table 3: cardiovascular diseases, ischemic diseases, hypertension, musculoskeletal disorders, neurological disorders, diabetes mellitus, kidney diseases, psychological disorders and insomnia and their relations with peptic ulcer in the studied population. $(\mathrm{N}=217)$

\begin{tabular}{|c|c|c|c|c|c|}
\hline & & \multicolumn{2}{|c|}{ Peptic ulcer } & \multirow{2}{*}{$\begin{array}{l}\text { Total } \\
(\mathrm{N}=217)\end{array}$} & \multirow{2}{*}{$\mathrm{P}$ value } \\
\hline & & $\begin{array}{l}\text { Yes } \\
(\mathrm{N}=46)\end{array}$ & $\begin{array}{l}\text { No } \\
(\mathrm{N}=171)\end{array}$ & & \\
\hline \multirow[t]{4}{*}{ Cardiovascular diseases } & \multirow[t]{2}{*}{ yes } & 38 & 129 & 167 & \multirow[t]{4}{*}{0.206} \\
\hline & & $82.6 \%$ & $75.4 \%$ & $77.0 \%$ & \\
\hline & \multirow[t]{2}{*}{ no } & 8 & 42 & 50 & \\
\hline & & $17.4 \%$ & $24.6 \%$ & $23.0 \%$ & \\
\hline \multirow[t]{4}{*}{ Ischemic diseases } & \multirow[t]{2}{*}{ yes } & 10 & 27 & 37 & \multirow[t]{4}{*}{0.228} \\
\hline & & $21.7 \%$ & $15.8 \%$ & $17.1 \%$ & \\
\hline & \multirow[t]{2}{*}{ No } & 36 & 144 & 180 & \\
\hline & & $78.3 \%$ & $84.2 \%$ & $82.9 \%$ & \\
\hline \multirow[t]{4}{*}{ Hypertension } & \multirow[t]{2}{*}{ yes } & 20 & 88 & 108 & \multirow[t]{4}{*}{0.213} \\
\hline & & $43.5 \%$ & $51.5 \%$ & $49.8 \%$ & \\
\hline & \multirow[t]{2}{*}{ no } & 26 & 83 & 109 & \\
\hline & & $56.5 \%$ & $48.5 \%$ & $50.2 \%$ & \\
\hline \multirow[t]{4}{*}{ Musculoskeletal disorders } & \multirow[t]{2}{*}{ yes } & 32 & 81 & 113 & \multirow[t]{4}{*}{0.006} \\
\hline & & $69.6 \%$ & $47.4 \%$ & $52.1 \%$ & \\
\hline & \multirow[t]{2}{*}{ no } & 14 & 90 & 104 & \\
\hline & & $30.4 \%$ & $52.6 \%$ & $47.9 \%$ & \\
\hline \multirow[t]{4}{*}{ Neurological disorders } & \multirow[t]{2}{*}{ yes } & 6 & 25 & 31 & \multirow[t]{4}{*}{0.500} \\
\hline & & $13.0 \%$ & $14.6 \%$ & $14.3 \%$ & \\
\hline & \multirow[t]{2}{*}{ no } & 40 & 146 & 186 & \\
\hline & & $87.0 \%$ & $85.4 \%$ & $85.7 \%$ & \\
\hline \multirow[t]{4}{*}{ Diabetes mellitus } & \multirow[t]{2}{*}{ yes } & 20 & 65 & 85 & 0.305 \\
\hline & & $43.5 \%$ & $38.0 \%$ & $39.2 \%$ & \\
\hline & no & 26 & 106 & 132 & \\
\hline & & $56.5 \%$ & $62.0 \%$ & $60.8 \%$ & \\
\hline Kidney diseases & diabetic & 6 & 5 & 11 & 0.001 \\
\hline & nephropathy & $13.0 \%$ & $2.9 \%$ & $5.1 \%$ & \\
\hline & chronic renal & 2 & 0 & 2 & \\
\hline & failure & $4.3 \%$ & $0.0 \%$ & $0.9 \%$ & \\
\hline & renal & 2 & 13 & 15 & \\
\hline & insufficiency & $4.3 \%$ & $7.6 \%$ & $6.9 \%$ & \\
\hline & N/A & 36 & 153 & 189 & \\
\hline & & $78.3 \%$ & $89.5 \%$ & $87.1 \%$ & \\
\hline Psychological disorders & yes & 10 & 21 & 31 & 0.086 \\
\hline & & $21.7 \%$ & $12.3 \%$ & $14.3 \%$ & \\
\hline & no & 36 & 150 & 186 & \\
\hline & & $78.3 \%$ & $87.7 \%$ & $85.7 \%$ & \\
\hline Insomnia & yes & 22 & 32 & 54 & 0.0001 \\
\hline & & $47.8 \%$ & $18.7 \%$ & $24.9 \%$ & \\
\hline & no & 24 & 139 & 163 & \\
\hline & & $52.2 \%$ & $81.3 \%$ & $75.1 \%$ & \\
\hline
\end{tabular}

\section{Discussion:}

Peptic ulcer disease (PUD) is a common disease of the digestive system ${ }^{[11]}$. Peptic ulcer disease is a problem of the gastrointestinal tract characterized by mucosal damage secondary to pepsin and gastric acid secretion.
It usually occurs in the stomach and proximal duodenum; less commonly, it occurs in the lower esophagus, the distal duodenum, or the jejunum. IT is a multifactorial health problem affecting almost all populations worldwide. In 
the United States, ulcers were a major cause of morbidity and lost productivity ${ }^{[12]}$. The selfreported PUD prevalence among people aged 18 years and older in the United States was $10.3 \%$ in $1989^{[13]}$, compared to $14 \%$ among people aged 20 to 81 years in Hong Kong ${ }^{[14]}$. This was a cross sectional study conducted among 217 of studied population. This study aimed to determine the prevalence and risk factors of PUD in elderly population of Arar city, Northern Saudi Arabia.Our study reported that $21.2 \%$ of participants had peptic ulcers. In Arar, Saudi Arabia another study conducted among 302 of studied population reported the prevalence of peptic ulcer was $21.9 \%^{[15]}$. In Taiwan a study was conducted among 572 of asymptomatic subjects, 9.4\% were diagnosed as having PUD [16]. In Shanghai, China a population-based endoscopic study reported that $17.2 \%$ of studied population had peptic ulcers ${ }^{[17]}$. However, it was substantially higher than the prevalence estimates reported in the two other studies, both of which were performed in Europe. The first of these studies found an overall prevalence of peptic ulcer of $4.1 \%{ }^{[18]}$ and the second found a slightly higher overall prevalence of $6.2 \%{ }^{[19]}$. In Iran another study conducted among 1011 participants reported the overall prevalence of peptic ulcer was $8.2 \%{ }^{[14]}$. This study found that from cases with peptic ulcer $56.5 \%$ were nonsmokers, $21.7 \%$ smokers and the same percent were Ex-smokers and there was a significant relation between peptic ulcer and smoking status $(\mathrm{p}=0.0001)$. Another study reported that among cases with peptic ulcer $50 \%$ were nonsmokers, $35.2 \%$ current smoker and $14.8 \%$ former smoker ${ }^{[16]}$. In china, another study reported from patients with peptic ulcer $51.7 \%$ current smoker, $44.3 \%$ never smoker and only $4 \%$ ex-smoker and current smoking was associated with a significant increase in the risk of PUD ${ }^{[17]}$. Another study found that PUD was significantly associated with being a current or former smoker which reported that $44.1 \%$ were nonsmoker, $29.4 \%$ smoker and $17.4 \%$ former smoker from patients with peptic ulcer ${ }^{[20]}$. A large US population-based study revealed that the prevalence of peptic ulcer in current and former smokers $(11.43 \%$ and $11.52 \%$ ) was almost doubled that of never smokers $(6.00 \%)^{[21]}$. It was also clear that the risk of peptic ulcers was associated with the quantity of tobacco use ${ }^{[22]}$. In USA another study reported from the patients with peptic ulcer $11.43 \%$ were current smoker, $11.52 \%$ former smoker and only $6 \%$ never smokers and found that smoking was significant predictor of $(\mathrm{p}<0.0001){ }^{[21]}$.Regarding to gender our study found that peptic ulcer was more prevalent among female than male by $73.9 \%$ vs $26.1 \%$ and there was a significant correlation between peptic ulcer and gender $(\mathrm{p}=0.003)$. Similar to this study in Arar, Saudi Arabia another study reported that peptic ulcer prevalence was higher in female than male $71.2 \%$ and $28.8 \%$, respectively, but with no significant effect $(\mathrm{p}=0.356){ }^{[15]}$. In contrast, another study reported that $77.8 \%$ of patients with peptic ulcer were male and $22.2 \%$ were females, therefore male gender was significantly higher in the PUD group $(p<0.001)^{[16]}$. Another study reported that peptic ulcer was more common in men than in women $61.9 \%{ }^{[17]}$. In Hong Kong, another study demonstrated that the prevalence of PUD was significantly higher in men than in women ${ }^{[14]}$. This study reported that $60.9 \%$ of patients with peptic ulcer were 60-70 years in age with no significant correlation $(\mathrm{p}=0.856)$. This was similar to another study conducted in Twain which found no significant correlation between age and peptic ulcer $(\mathrm{p}=0.082)^{[16]}$. Another study found that individuals aged 40-49 years were significantly more likely to have PUD than those aged 30-39 years ${ }^{[17]}$. Another study found that the prevalence of peptic ulcer was high in age $18-25$ years $42.4 \%$, however there was no statically significance $(\mathrm{p}=0.270)^{[15]}$. Another study found that patients with PUD were significantly older than those without PUD ${ }^{[14]}$.Our study found that there was a significant association between educational status and peptic ulcer $(p=0.034)$. Another study demonstrated that subjects with low education level had a higher risk of peptic ulcer $(p=0.045){ }^{[16]}$.In China, another study reported that there was no significant association with education level $(p>0.05)^{[17]}$. In Arar, another study reported a significant correlation between peptic ulcer and educational level $(\mathrm{p}=0.588){ }^{[15]}$.As regards BMI, our study reported that $39.1 \%$ of patients with peptic ulcer were obese which less than non-peptic ulcer patients $45.6 \%$ and there was no significant association between BMI and peptic ulcer $(\mathrm{p}=0.279)$. Another study found that the PUD group had higher BMI than the 
non-PUD group and revealed a strong positive association between BMI and PUD ${ }^{[16]}$. Another study reported that the prevalence of PUD was significantly lower in individuals with high BMI of $\geq 27.5 \mathrm{~kg} / \mathrm{m} 2$ than those with low BMI of $18.5-22.9 \mathrm{~kg} / \mathrm{m} 2^{[17]}$. Aro et al. ${ }^{[23]}$ found that obesity may be an independent predictor of peptic ulcer disease. According to association between peptic ulcer and other chronic diseases this study reported that from cases with peptic ulcer $82.6 \%$ had cardiovascular diseases, $21.7 \%$ had ischemic diseases, diabetes mellitus and hypertension $43.5 \%$ and kidney diseases (Diabetic nephropathy $13 \%$ and $4.3 \%$ for both chronic renal failure, renal insufficiency). Another study reported chronic medical conditions. $19.65 \%$ heart diseases, $23.79 \%$ kidney diseases, COPD $22.68 \%$ and diabetes $14.6 \%$ ${ }^{[22]}$. Patients with renal insufficiency have been noted in studies to have higher incidence of peptic ulcer disease than controls, notwithstanding hemodialysis ${ }^{[24,25]}$. Coronary artery disease had been previously associated with peptic ulcer disease and dyspeptic symptoms ${ }^{[26]}$. Alternatively, diabetes is not known to be associated with peptic ulcer disease. In fact, according to Duggan et al. ${ }^{[27]}$, it was reported to have an antagonist effect, possibly may be due to anomalous insulin metabolism in duodenal ulcer patients.

Conclusion: among the elderly participants, $21.2 \%$ suffered from peptic ulcer. There was significant relations between peptic ulcer with gender, smoking status, musculoskeletal disorders, kidney diseases and insomnia. While, there was insignificant relations between peptic ulcer with age group and BMI group.

\section{References:}

1. Najm WI (2011): Peptic ulcer disease. Primary Care, 38(3): 383394.

2. Sung JJ, Kuipers EJ and El-Serag HB (2009): Systematic review: the global incidence and prevalence of peptic ulcer disease. Aliment. Pharmacol. Ther., 29:938-946.

3. Aro P, Storskrubb T, Ronkainen J et al. (2006): Peptic ulcer disease in a general adultpopulation: the Kalixanda study: a ran-dom population-based study. Am. J. Epi-demiol., 163: 10251034.
4. Borum ML (1999): Peptic-ulcer disease in the elderly. Clin. Geriatr. Med., 15(3):457-571

5. Militello C, Volpin E, De Santis et al. (1997): Complications of peptic ulcer disease in the elderly. Chir. Ital.,49(4-5):37-341.

6. Kurata JH and Nogawa AN (1997): Meta-analysis of risk factors for peptic ulcer. Nonsteroidal anti-inflammatory drugs,Helicobacter pylori and smoking. J. Clin. Gastroenterol., 24:217.

7. Ziegler AB (2005): The role of proton pump inhibitors in acute stress ulcer prophylaxis in mechanically ventilated patients. Dimens. Crit. Care Nurs.,24:109-114.

8. Milosavljevic T, KostićMilosavljević M, Jovanović I et al. (2011): Complications of peptic ulcer disease. Digestive Diseases, 29(5): 491-503.

9. Mustafa M, Iftikar M, Rajesh K $e t$ al. (2015): Role of Heliocobacter pylori infection in peptic ulcer disease. International Journal of Research in Applied, Natural and Social Sciences, 3(8): 29-38

10. Ramakrishnan $K$ and Salinas RC (2007: Peptic ulcer disease. Am. Fam. Physician, 76(7):1005-1012.

11. Chan FK, Leung WK (2002): Pepticulcer disease. Lancet,360:933-941.

12. Sonnenberg A (1994): Peptic ulcer. In: Everhart JE, ed. Digestive diseases in the United States: epidemiology and impact.Washington, DC: US Government Printing Office.

13. Sonnenberg A (1996): The prevalence of self-reported peptic ulcer in the United States. Am. J. Public Health, 86:200-205.

14. Xia B, Xia HH, Ma CW et al. (2005): Trends in the prevalence of peptic ulcer disease and Helicobacter pylori infection in family physicianreferred uninvestigated dyspeptic patients in Hong Kong. Aliment. Pharmacol. Ther., 22:243-249.

15. Albaqawi AS, el-Fetoh NMA, Alanazi RF et al. (2017): Profile of peptic ulcer disease and its risk factors in Arar, Northern Saudi Arabia. 
Electronic Physician, 9(11):57405745.

16. Wang F, Tu M, Mar G et al. (2011): Prevalence and risk factors of asymptomatic peptic ulcer disease in Taiwan. World Journal of Gastroenterology,17(9):1199-1203.

17. Li Z, ou D, Ma $X$ et al. (2010): Epidemiology of peptic ulcer disease: endoscopic results of the systematic investigation of gastrointestinal disease in China. Am. J. Gastroenterol., 105:2570-2577.

18. Aro P, Storskrubb T, Ronkainen J et al. (2006): Peptic ulcer disease in a general adult population: the Kalixanda study: a random population-based study. Am. J. Epidemiol., 163:1025-1034.

19. Barazandeh F, Yazdanbod A, Pourfarzi F et al. (2012): Epidemiology of Peptic Ulcer Disease: Endoscopic Results of a Systematic Investigation in Iran. Middle East Journal of Digestive Diseases, 4(2):90-96.

20. González-Pérez A, Sáez ME, Johansson S et al. (2014): Risk factors associated with uncomplicated peptic ulcer and changes in medication use after diagnosis. PLoS ONE, 9(7): 101768-101776 .

21. Garrow D and Delegge MH (2010): Risk factors for gastrointestinal ulcer disease in the US population. Dig. Dis. Sci., 55:66-72.

22. Chen MH, Wu MS, Lee WC et al. (2002): A multiple logistic regression analysis of risk factors in different subtypes of gastric ulcer. Hepatogastroenterology, 49:589-592.

23. Aro P, Storskrubb T, Ronkainen J et al. (2006): Peptic ulcer disease in a general adult population: the Kalixanda study: a random population-based study. Am. J. Epidemiol., 163(11):1025-1034.

24. Kang JY, Wu AY, Sutherland IH et al. (1988): Prevalence of peptic ulcer in patients undergoing maintenance hemodialysis. Dig. Dis. Sci., 33(7):774-778.

25. Var C, Gultekin F, Candan F et al. (1996): The effects of hemodialysis on duodenal and gastric mucosal changes in uremic patients. Clin. Nephrol., 45(5):310-314.

26. Banic M, Sutlic Z, Biocina B et al. (2005): Peptic ulcer disease in dyspeptic patients with ischemic heart disease: search and treat? $\mathrm{Z}$. Gastroenterol., 43(6):581-586.

27. Duggan JM, O'Keefe EA, Weaver AL et al. (1992): Diabetes mellitus and operated peptic ulcer disease. J. Gastroenterol. Hepatol.,7(3):308-312. 